\title{
LETRAMENTO DIGITAL, PRÁTICAS SOCIAIS E IMPLICAÇÕES PEDAGÓGICAS
}

\author{
DIGITAL LITERACY, SOCIAL PRACTICES AND \\ PEDAGOGICAL IMPLICATIONS
}

\author{
Rosiney Aparacida Lopes do Vale* \\ Marilúcia Santos Domingos Striquer ${ }^{* * *}$
}

Resumo: As atuais formas de leitura decorrem do surgimento de novas práticas sociais, oriundas da vida moderna que, por sua vez, requerem que o sujeito assuma outras ou novas habilidades para lidar com as atividades de leitura e escrita. Numa retrospectiva histórica, constatamos que, da antiguidade clássica até a modernidade, deparamo-nos com uma série de modificações no ato de ler, dependendo das diferentes materialidades que serviram de suporte para os textos. Posto que o surgimento do computador e, mais ainda, da Internet desencadeou novos elementos para se pensar a questão do letramento, redirecionando os modos de ver esse novo conceito, pretendemos, no presente artigo, apresentar uma breve explanação sobre a história da leitura, enfocando as mudanças dos suportes, bem como a mudança no perfil dos leitores frente ao surgimento de novas tecnologias. Apresentamos também uma experiência que tivemos com uma professora do ensino fundamental II, no laboratório de informática de uma escola estadual, e propomos uma reflexão sobre o papel do professor diante da necessidade de lidar com novas ferramentas na prática docente.

Palavras-Chave: Letramento digital; História da leitura; Ensino de leitura

ABSTRACT: The present forms of reading emerge from new social practices, derived from modern life that demands that the subject adopts other or new abilities to deal with the reading and writing activities. A historical retrospective demonstrates that, from classical antiquity to modernity, there has been a series of modifications in the act of reading, depending on the different materialities that supportedthe texts. Because of the emergence of the computer and, in particular of the Internet that contributed with new elements to think about literacy, changing the forms of understanding this new concept, this article intends to present a brief explanation

\footnotetext{
" Mestre em Filologia e linguística da língua portuguesa. Professora da Universidade Estadual do Norte do Paraná (UENP), campus de Jacarezinho. E-mail: rosineyvale@uenp.edu.br

"** Professora Adjunta da Universidade Estadual do Norte do Paraná (UENP), campus Jacarezinho. Doutora em Estudos da Linguagem.E-mail: marilucia@uenp.edu.br.
} 
of the history of reading, focusing on the changes of support, as well as the change in readers' profile due to the new technologies. The article also presents athe experienceof a teacher fromthe final years of elementary schoolin the computer lab of a state school, and proposes a reflection about teachers' role concerningthe need to deal with new tools in their teaching practices.

KEYWoRDs: Digital literacy; History of reading; Teaching of reading.

\section{INTRODUÇÃO}

As atuais formas de leitura decorrem do surgimento de novas práticas sociais, oriundas da vida moderna que, por sua vez, requerem que o sujeito assuma outras ou novas habilidades para lidar com as atividades de leitura e escrita, como, por exemplo, para fazer uso de ferramentas como o cartão magnético, o caixa eletrônico, as redes sociais virtuais, hoje, comuns à vida dos cidadãos. Dessa forma, as discussões sobre o conjunto de capacidades de todas as ordens necessárias à execução das diversas práticas de leitura vêm crescendo acentuadamente, e, nas últimas décadas, o assunto ganhou ainda mais repercussão e passa por diversas mudanças de foco na busca de que tais discussões contribuam para que as práticas de leitura estejam cada vez mais afinadas com as necessidades reais dos leitores.

Daí a urgência das instituições escolares assumirem a missão de desenvolverem tais capacidades, no caso, desenvolverem as capacidades de linguagem de seus alunos para que eles possam participar das diversas e diferentes práticas de leitura e escrita existentes atualmente na sociedade. Isto é, é dever da escolar, de acordo com a Diretriz Estadual de Educação (PARANÁ, 2009), levar o aluno a ter capacidades para ler uma notícia, seja em jornal impresso ou em um site na internet; ler um texto de opinião em um blog; se relacionar com outra pessoa via facebook; enviar um currículo para uma empresa via e-mail; se cadastrar em um curso a distância na homepage do curso etc. Ocorre que, de um modo geral, as pessoas participam cotidianamente de práticas sociais diversificadas, mediadas pela leitura e pela escrita, ou ainda, estão imersos em práticas de letramento.

Portanto, nossa compreensão e defesa é a de que cabe a escola criar, continuamente, práticas de letramento no sentido que Baltar (2008) lhe conferem: projetos que organizam "estratégias de ensinagem para que os estudantes tenham acesso a práticas letradas situadas, [e que] também viabilizam o agir desses estudantes em atividades significativas de linguagem que ocorrem em diferentes esferas sociais" (BALTAR, 2008, p. 564-inserção das pesquisadoras).

Este artigo, então, tem o objetivo de apresentar uma breve explanação sobre a história da leitura, enfocando as mudanças dos suportes, bem como a mudança no perfil dos leitores frente ao surgimento de novas tecnologias, e propor uma reflexão sobre o papel do professor diante dos letramentos digitais. 
BREVE HISTÓRIA DA LEITURA: SUPORTES E LEITORES

Em História da leitura no mundo ocidental, Cavallo e Chartier (2002) expõem que:

Todos aqueles que podem ler os textos não os leem da mesma forma e, em cada período, é grande a distância entre os grandes letrados e os menos hábeis leitores. Contrastes, igualmente, entre normas e convenções de leitura que definem, para cada comunidade de leitores, usos legítimos do livro, maneiras de ler, instrumentos e processos de interpretação. Contrastes, enfim, entre as expectativas e os interesses muito diversificados que os diferentes grupos investem na prática da leitura (p.6).

A afirmação supracitada ilustra o quão densas foram as mudanças ocorridas com o ato de ler, desde a antiguidade, e o quão importante é o conhecimento das etapas pelas quais a leitura passou até os dias atuais, para compreendermos melhor os elementos que permeiam a relação leitura/leitor. Afinal, é a partir do conhecimento das práticas do passado que podemos refletir sobre as atuais, num exercício de compreensão e tentativa de não cometer os mesmos erros e de aprimoramento de novas ações.

Da antiguidade clássica até á modernidade, deparamo-nos com uma série de modificações no ato de ler. Inicialmente, referimo-nos aqui ao período que abrange a civilização grega e a romana, observamos o uso de diferentes materialidades que serviram de suporte para os textos, dentre eles: as tabuinhas feitas de argila ou madeira, o livro na forma de rolo (o livro-rolo de papiro), também chamado de volumen, e o códice (ou códex), livro já com páginas, que irá substituir o rolo a partir do sec. II d. C. O códice apresentava um custo menor, na medida em que se podiam utilizar os dois lados do suporte. Fora do Egito, o produto utilizado para a confecção do códice era o pergaminho, produto animal que podia ser preparado em toda parte. "O códex coloca-se como instrumento mediador entre a leitura na Antiguidade e as maneiras de ler na Idade Média" (CAVALLO; CHARTIER, 2002, p.19).

Com o passar do tempo, as páginas do códice e o pergaminho foram substituídas pelo papel, e, atualmente, temos ainda a tela do computador como um novo espaço para a escrita e para a leitura dos escritos (SOARES, 2012). O que não significa simples mudança de suporte, uma vez que, segundo Cavallo e Chartier (2002),

As formas produzem sentido e que um texto se reveste de uma significação e de um estatuto inéditos quando mudam os suportes que o propõem à leitura. Toda história das práticas de leitura é, portanto, necessariamente uma história dos objetos escritos e das palavras leitoras (p. 6).

Assim, os referidos autores enfatizam a existência de diferenças entre os sentidos atribuídos pelo autor e por seus leitores, destacando as diversas possibilidades de interpretação de uma obra, acarretadas, dentre outros fatores, pelo suporte que a veicula, posto que o texto não é uma abstração, ele só existe graças à maneira como é transmitido. 
De forma um pouco mais específica sobre os textos veiculados pelas práticas digitais, ou virtuais, defende Chartier (1998) que,

A inscrição do texto na tela cria uma distribuição, uma organização, uma estruturação do texto que não é de modo algum a mesma com a qual se defrontava o leitor do livro em rolo da Antiguidade ou o leitor medieval, moderno e contemporâneo do livro manuscrito ou impresso, onde o texto é organizado a partir de sua estrutura em cadernos, folhas e páginas. $\mathrm{O}$ fluxo sequencial do texto na tela, da continuidade que lhe é dada, o fato de que suas fronteiras não são mais tão radicalmente visíveis, como no livro que encerra, no interior da sua encadernação ou de sua capa, o texto que ele carrega a possibilidade para o leitor de embaralhar, de entrecruzar, de reunir textos que são inscritos na mesma memória eletrônica: todos esses traços indicam que a revolução do livro eletrônico é uma revolução nas estruturas do suporte material do escrito assim como nas maneiras de ler (p. 12-13).

É nesse sentido que Soares (2002) defende que a leitura - e também a escrita -, feita por meio da tela de um computador acarreta outras formas de letramento, apontando, então, para um "letramento digital", e ainda destaca as possíveis "mudanças sociais, cognitivas e discursivas" geradas pelo suporte.

Em convergência, Goulart (2011) afirma que,
O modo como o texto se estrutura no computador (incluindo a apresentação e a formatação do texto) dimensiona a materialidade de texto de um modo diferente daquele lido ou escrito no papel. A própria maneira como o "manuseamos", indo e voltando, fazendo destaques, inserções, entre outras ações, nos obriga a novos conhecimentos e novas estratégias de leitura e de escrita (p. 54).

Enfim, para Chartier (apud SOARES, 2002), "o texto na tela [é] uma revolução do espaço da escrita que altera fundamentalmente a relação do leitor com o texto, as maneiras de ler, os processos cognitivos" (p. 152 -inserção da pesquisadora). E, mais que isso, essa mudança de suporte acarreta o que se tem chamado de "um novo letramento, isto é, um novo estado ou condição para aqueles que exercem práticas de escrita e de leitura na tela" (CHARTIER apud SOARES, 2002, p. 152), o já mencionado letramento digital. Enfim, são as mudanças de suporte convergindo para uma concomitante mudança de perfil também dos leitores, e também passam pela questão da postura física (corporal) diante do texto, pelas escolhas, pelos comportamentos e pelas estratégias de abordagem ao texto.

LETRAMENTO DigiTAL: MESMOS CAMINHOS, NOVOS RUMOS

Pensar a questão do letramento nos interessa no sentido de buscar verificar o que de fato muda com as novas práticas de leitura, possibilitadas pelo computador ligado à internet. Em decorrência de nosso foco é 
que primeiramente reconhecemos a definição que Soares (2002) atribui à noção de letramento, explicada pela autora. Segundo esta há uma

Imprecisão que, na literatura educacional brasileira, ainda marca a definição de letramento, imprecisão compreensível se se considera que o termo foi recentemente introduzido nas áreas das letras e da educação. Entretanto não há, propriamente, uma diversidade de conceitos, mas diversidade de ênfases na caracterização do fenômeno (p. 144).

Ou seja, de acordo com a autora, o termo letramento é recente e surgiu justamente a partir da necessidade de se observar o estado de quem sabe ler e escrever, em contraposição a uma preocupação anterior, que se voltava apenas para o estado ou condição de alfabetismo. Tal necessidade veio como consequência da compreensão de que é preciso não apenas saber ler e escrever, mas saber fazer uso efetivo da leitura e da escrita, respondendo às demandas sociais.

Nessa mesma linha de raciocínio, Kleiman (1995, p. 19) considera que "podemos definir hoje o letramento como um conjunto de práticas sociais que usam a escrita, enquanto sistema simbólico e enquanto tecnologia, em contextos específicos, para objetivos específicos".

O surgimento do computador e, mais ainda, da Internet, nesse contexto, veio trazer novos elementos para se pensar a questão do letramento, redirecionando os modos de ver esse novo conceito, uma vez que não apenas indicou novos modos de estar na sociedade como trouxe a linguagem escrita para o cotidiano de crianças e jovens em idade escolar.

Soares (2005, p.47) explica que alfabetizar e letrar são duas ações distintas, mas inseparáveis, pois o ideal seria alfabetizar letrando, ou seja, ensinar a ler e escrever no contexto das práticas sociais da leitura e da escrita, de modo que o indivíduo se tornasse, ao mesmo tempo, alfabetizado e letrado. $E$ isso inclui, no atual contexto, os usos de escrita que caracterizam a entrada do computador conectado à Internet na vida das pessoas, letrando-as, inclusive, digitalmente. Afinal, não é mais possível ficar alheio às mudanças que essas novas formas de comunicação digital trouxeram para a nossa vida cotidiana, independentemente da escola.

No contexto atual, os processos de interação passam a envolver novas formas de conhecimento estratégico ou esquemas para lidar com tecnologias na vida diária e habilidade para ler/produzir textos típicos da era da multimídia e da informação. Em outras palavras, ao lado dos textos impressos, da exigência de saber ler criticamente, recuperar e processar informação, agora também se faz necessário, entre outras coisas, saber lidar com imagens e representações gráficas.

Por conseguinte, se discutir letramento já não era/é uma tarefa fácil. Como vemos, no contexto atual, esses novos elementos relacionados à era digital vêm acalorar a discussão, fazendo com que repensemos as nossas ações, bem como a nossa prática pedagógica.

E nesse universo de modificações e exigências de novas habilidades de letra- 
mento, atesta Rojo (2007), os atos de ler e escrever são ainda mais fundamentados na interação virtual que em nossas interações cotidianas, no mundo atual, o que torna relevante e urgente o estudo e a discussão sobre letramentos digitais.

Assim, pensar no tema Letramento Digital leva-nos a ponderar sobre os impactos das novas tecnologias nas práticas letradas e de ensino e a observar que os eventos de letramento que ocorrem com a intermediação da Internet exigem novas práticas e habilidades de leitura e de escrita (SOARES, 2002). Por certo, a reflexão gira em torno do modo como esses novos suportes, em especial o computador, podem ser ferramenta útil também na escola, no apoio às práticas pedagógicas, simplificando e dinamizando o cotidiano da sala de aula.

Vale lembrar que "o termo ' tecnologia da informação' não é, necessariamente, sinônimo de computador hardware e software. Todavia o computador pode ser considerado como o principal representante dessa tecnologia (...)". (NETO, 2006, p. 51) A novidade do computador é que, segundo Chartier (1998) pela primeira vez, no mesmo suporte, o texto, a imagem e o som podem ser conservados e transmitidos. Todas mídias muito conhecidas das sociedades atuais, mas que agora se apresentam simultaneamente.

O PROFESSOR COMO MEDIADOR DE CONHECIMENTOS: A LEITURA NA ERA DIGITAL

Em concordância com Coscarelli (2006), apregoamos que não há dúvidas de que o advento da internet provocou mu- danças consideráveis em nossa sociedade. Dentre essas mudanças, merece destaque a criação de outros gêneros textuais, somando-se aos tantos que já circulam em nossa sociedade letrada. "Entre eles, podemos citar o chat, o hipertexto, a multimídia, a hipermídia, os banners publicitários, a literatura digital em toda a sua diversidade e, provavelmente, alguns outros que ainda não somos capazes de mencionar" (COSCARELLI, 2006, p.65)

Então, nesse oceano de novos gêneros textuais e, consequentemente, de novas práticas e demandas sociais, o papel do professor, como mediador, pensando numa concepção de ensino e de aprendizagem que visem a um ensino como construção de conhecimento, como uma via de mão dupla, implicando o diálogo e, portanto, não tratando os aprendizes como máquina decodificadoras, ganha um contorno especial (RIBEIRO, 2006, p.90). Não que o professor não tenha sido visto como figura importante no processo de ensino e de aprendizagem, mas hoje isso se torna ainda mais patente, uma vez que,

O professor precisa, então, além de guiar-se pelas orientações dadas pelos PCN, atualizar-se com relação às tecnologias intelectuais disponíveis no mundo de hoje". (...) 'É, hoje, tarefa do professor ensinar' os alunos a buscar a informação e a fazer a triagem dela (RIBEIRO, 2006, p. 86- 87- grifos do autor).

Os professores precisam encarar esse desafio de se preparar para essa nova realidade, aprendendo a lidar com os recursos básicos e planejando formas 
de usá-los em suas salas de aula (COSCARELLI, 2011, p. 31).

Esses encaminhamentos são necessários em função de todo aparato tecnológico,

dos gêneros que deles emergiram e, principalmente, da mudança que eles causaram nas orientações às práticas pedagógicas docentes que preocupam os professores, gerando, às vezes, desconfiança e medo nesses profissionais, pois vários elementos estão envolvidos nessa trama. Se antes já era difícil ensinar os alunos a ler no papel impresso, a fazer a chamada leitura crítica, reflexiva que vem sendo alardeada há muito tempo, como então proceder diante desse novo suporte de leitura? Como orientar a leitura desses alunos? Como colaborar para que não se percam no emaranhado de informações que a internet veicula? "Como auxiliá-los a estabelecer uma interação dialógica com os conteúdos abordados na rede, na perspectiva bakhtiniana do termo?" (SANTOS, 2003, p.308). Que tipo de navegação propor aos alunos? Como lidar com o hipertexto digital? Novas tecnologias para quê e por quê? (GOULART, 2011).

Antes, porém, de procurarmos respostas para todas essas questões, faz-se necessário perceber que inovações tecnológicas não significam, literalmente, inovações pedagógicas; não basta apenas trocar as práticas educativas. Só é possível utilizar os recursos tecnológicos na sala de aula como ferramentas de auxílio para o ensino e para a aprendizagem escolar a partir do momento que o professor faz opções, as quais revelam suas concepções de ensino e de aprendizagem, isto é, conforme a noção que o professor tem desses processos e do que sejam as devidas ferramentas é que ele direcionará suas ações didáticas. Isso porque, conforme Corrêa (2006),

Os recursos tecnológicos são mutáveis e o sujeito é quem determina o uso que fazemos desses recursos. Essas intenções se referem aos paradigmas educacionais e comunicacionais presentes na escolha e na utilização dos diferentes recursos tecnológicos (p. 44).

O computador, por si só, não vai mudar a educação, não vai mudar as concepções de professor/aluno e de ensino/aprendizagem que os envolvidos na educação têm. São os objetivos, os conteúdos curriculares tomados como objeto de ensino, o contexto imediato que comandam as ações pedagógicas, pois, assim, como defende Coscarelli (2011, p. 27), "cada situação de aprendizagem requer uma estratégia diferente, e o computador pode ser útil em várias dessas ocasiões, bastando para isso que o professor planeje atividades, mais dirigidas ou menos, conforme o momento".

Em decorrência, orienta Corrêa (2006) que,

Devemos construir uma nova articulação entre tecnologia e educaçãoaquilo que chamaríamos de uma visão crítica, apesar do desgaste da palavra "crítica"-ou seja, compreender a tecnologia para além do mero artefato, recuperando sua dimensão humana e social. As tecnologias que favorecem o acesso à informação e aos canais de 
comunicação não são por si mesmas, educativas, pois, para isso, dependem de uma proposta educativa que as utilize enquanto mediação para uma determinada prática educativa (p. 4647).

Nesse contexto, na era digital que se consolida, mais uma vez, e não poderia ser diferente, a missão a ser cumprida tem de ser realizada a várias mãos; o professor não pode ser visto como um ser isolado e nem tão pouco como o responsável pelos problemas. Ele não é o vilão do cenário, há questões bem abrangentes que permeiam essa discussão, como bem pontua Coscarelli (2011, p. 31): "Aproveito para alfinetar a universidade e os centros de formação de professores: o que têm feito para preparar os professores para essa realidade?". E muitas outras questões poderíamos também somar a essas; e não se trata de defender a escola ou o professor, mas tão somente de ampliar a visão em relação aos problemas que se delineiam.

Em favor disso, podemos citar, por exemplo, a investigação realizada por Santos (2003), buscando esclarecer modalidades de uso da internet em situações de ensino fundamental. Sua pesquisa revelou que

Os professores demonstraram interesse e vontade de inovar, mas estavam de mãos vazias, sem instrumentos teóricos e empíricos para isso, de modo que o uso da internet ainda é bastante limitado, embrionário e aquém das possibilidades desse poderoso meio de comunicação e informação (SANTOS, 2003, p. 311).
E, ressaltamos, assim configura-se uma situação histórica na qual não é mais possível falsear a educação. Os caminhos precisam ser repensados e planos traçados para que, mais do que discutir conceitos e nomenclaturas, possamos refletir sobre meios para tornar a escola um espaço que realmente esteja focado em ampliar as possibilidades dos leitores no uso desse novo suporte, o computador, apontando meios para o enfrentamento pedagógico dessa questão, e alargando o universo das práticas sociais necessárias à vida em sociedade. Referimo-nos ao dever da escola, e nesse caso dos professores, de, no processo de ensino e de aprendizagem, articular as referências de mundo que os alunos já possuem com as novas tecnologias, oportunizando, assim, maior acesso à inclusão social e, consequentemente, maior acesso aos bens culturais produzidos pela humanidade.

A rigor, é necessário tornar os leitores/ alunos manipuladores de textos e suportes, exploradores de possibilidades (RIBEIRO, 2011, p.135). Mesmo sendo fruto de tempos de computadores e demais instrumentos de comunicação digitais e, principalmente da internet, nossos alunos, mesmo dominando com maior naturalidade esses recursos, não prescindem da figura do professor, que faça a mediação entre as informações veiculadas e os modos de registrar e trabalhar, no sentido de organizar, todo esse arsenal a que serão expostos.

Quanto aos professores, há uma cobrança para que se adaptem a essa nova realidade, uma cobrança que gera desconforto, na medida em que o seu aprendizado fora 
baseado em outros recursos. O novo geralmente assusta, mas não podemos permitir que numa sociedade em constante mutação a educação permaneça estática, arcaica e avessa às novas necessidades de seus atores. ${ }^{1}$ Nunca foi tão necessário ensinar a ler e a escrever, pois, conforme postula Carrière (apud MARCUSCHI, 2003), uma pessoa só pode utilizar um computador se ela souber ler e escrever, o que exige ainda, diferente de antigamente, mais conhecimentos sobre novos signos não verbais.

A fim de averiguar no nosso entorno como os professores estavam agindo diante da tarefa de lidar com atividades que envolvessem os alunos e o laboratório de informática, acompanhamos uma professora de uma escola pública do município de Jacarezinho/PR, durante um mês. A referida professora, formada no curso de Letras desde 1987, levava os seus alunos do $6^{\circ}$ ano do ensino fundamental, período da tarde, para o laboratório de informática, pelo menos uma vez por mês. A frequência era essa porque havia outros professores e outros alunos que precisavam se reversar para usar o laboratório.

Nossa intenção ao acompanhar a professora era analisar o modo como ela preparava as atividades que iriam ser propostas para os alunos e como conseguia dar conta de auxiliá-los.

Para a coleta de dados, optamos pela observação direta das aulas no laboratório de informática. Para o momento, relatamos

\footnotetext{
${ }^{1}$ Estamos nos referindo aos docentes, em sua maioria, que ainda são da mesma geração da década de 90 , que não conviveram com as TIC desde pequenos.
}

o desenvolvimento de uma atividade (a criação de um e-mail pelos alunos) que a professora propôs, e que foi desenvolvida em um dia, em dois horários, cada um com $50 \mathrm{~min}$.

O laboratório de informática estava equipado com 42 computadores, que operam com o sistema Linux. Posto que nem todos os equipamentos estavam em condição de uso, a maioria dos alunos tinha que se sentar em dupla. Havia também algumas dificuldades tais como: internet muito lenta e travando, isso quando não caia e os alunos tinham que reiniciar as atividades, tornando a prática cansativa e desanimadora para a maioria deles.

Apesar das dificuldades técnicas citadas, e da dificuldade de alguns deles quanto ao próprio manuseio do computador, o objetivo da aula, que era criar um e-mail, a partir das instruções lidas no site Yahoo, foi cumprido e em tempo hábil. Alguns alunos necessitaram da ajuda da professora, outros, mais rápidos e habituados com o uso do computador, deram conta da atividade e dedicaram-se a auxiliar ou a atrapalhar os colegas. A professora demonstrou não saber bem o que fazer em vários momentos.

A esse respeito, faz-se pertinente os dizeres de Carla Viana Coscarelli em seu artigo "Alfabetização e letramento digital", quando menciona que "o fato de usar a informática nas aulas não transforma instantaneamente o ensino em alguma coisa 'moderna' ou 'eficiente'" (2011, p. 26). Tais palavras fazem sentido nesse contexto, na medida em que, muito embora a professora demonstrasse as melhores intenções e fosse muito dedicada, percebemos que 
lhe faltavam instruções para que houvesse de fato uma finalidade naquilo que se propunha. A insegurança dela deixava os alunos dispersos e inquietos. Durante a atividade, alguns alunos questionaram: "professora, pra que serve o e-mail?".

Acreditamos que a escolha dessa atividade, pela professora, poderia se caracterizar como produtiva, e segundo Coscarelli (2011), é uma atividade prazerosa e que contribui para o letramento digital dos alunos. A autora ressalta que a estrutura do texto e-mail, as formas de fazer abertura e fechamento desse gênero textual, as variações de registros usados nele, bem como abreviações, emoticons, etiquetas da Net são assuntos que podem ser abordados e discutidos com os alunos. No entanto, não foi isso que presenciamos durante a aula observada. Nesse caso específico, a atividade ficou restrita a produção do e-mail como já mencionado, não houve "gancho" com a sua disciplina em nenhum momento e em nenhum sentido. Tão pouco a professora conseguiu "controlar" a leitura dos alunos sobre as instruções de como fazer o e-mail, os passos a serem seguidos.

Lembramos, ainda, que minutos antes de acabar a aula, a professora pediu para que os alunos copiassem o Login e a senha no caderno. Muitos não sabiam o que Login significava e por isso, não conseguiam associar sua função. Não foi trabalhado, por exemplo, o envio do e-mail entre os eles, o que poderia ser avaliado como resultado positivo ou negativo, quem sabe, acerca dos objetivos e resultados finais pressupostos para essa determinada aula. Além do que, seria uma ótima oportunidade pra o entretenimento, para a diversão e aprenderiam muito com essa "brincadeira séria".

Nesse sentido, relembramos o alerta de Coscarelli sobre a necessidade de "os professores se preparem para operar desembaraçadamente com esse instrumental. Isso não significa ser expert em informática, mas familiarizar-se com os recursos básicos necessários à utilização dessa tecnologia" (2011, p. 40).

Quanto ao comportamento dos alunos, eles ficaram muito agitados e pediram ajuda o tempo todo, falaram e riram alto, tornando o ambiente, a maioria das vezes, ensurdecedor. A professora sozinha, sem auxilio não deu conta de controla-los, além do que, queriam terminar tudo "correndo" para entrar nos "joguinho".

No que tange ao interesse pelas aulas ditas "diferentes", é evidente que ele existe. As crianças adoram o fato de usar o computador, no entanto o que pode prejudicar o andamento das tarefas é o fato de elas terem que fazer atividades para as não veem tem sentido. Na outras aulas presenciadas, muitas relutaram em realizar a tarefa, alegando que era "muito chata", "sem graça", "pra que vim aqui fazer isso?".

Enfim, observamos que, embora a professora seja muito dedicada e tenha um objetivo ao propor a atividade, não consegue deixar isso claro para os alunos. Isso prejudica o andamento da aula. Desse modo, ao usar o computador como meio alternativo para trabalhar, foi perceptível sua falta de habilidade e mesmo de entendimento sobre o que estava fazendo. A impressão que 
tivemos é que a professora queria usar o laboratório mais para parecer mostrar que estava atenta às práticas modernas de ensino-aprendizagem. Porém, dado o exposto, as atividade ficavam restritas ao entretenimento.

Ratifica-se com isso, o que Santos (2003) expôs sobre o interesse e a vontade de inovar dos professores e das dificuldades que enfrentam com a falta de instrumentos teóricos e empíricos para isso. Há muito que se fazer ainda, para que o trabalho com a leitura e a escrita nas escolas, via meios tecnológicos, nesse caso o computador e a internet, se tornem realmente eficazes. Não adianta sair da sala de aula, trocar a lousa pela tela do computador, se não houver antes disso um entendimento do que se vai fazer. A prática docente aponta para novos aprendizados, e o professor como mediador de conhecimentos está diante de mais um desafio.

E a tarefa não é fácil. Realmente são muitas as angústias, as indagações, as dúvidas, os medos, os anseios e os desejos. De nossa parte, colocamo-nos no mesmo patamar daqueles que buscam respostas para as suas inquietações ( $\mathrm{O}$ quê fazer? Como fazer?) e vamos erguendo castelos que ora parecem construídos em terra firme ora sobre areia movediça.

\section{CONSIDERAÇÕES FINAIS}

Posto que nossa pretensão neste texto, não fora trazer respostas, esperamos que os pontos arrolados, embora breves, tenham sido suficientes para evidenciar o quão fe- cundos são os campos a serem explorados no terreno da leitura e das novas tecnologias e o quão diversas são as formas de abordagem, diversas, mas não menos importantes umas das outras.

É bom lembrar que a história da leitura e dos seus suportes, como também a da humanidade de maneira geral, é história de adaptação, sempre. A rigor, não há nada que se possa dizer completamente estranho, por mais que isso possa parecer; o que, na verdade, o leitor faz

É reconhecer certas características, deduzir outras, empregar a familiaridade que já possui, sua experiência de leitura pregressa, num suporte que demandará novas reações. Ao explorar o novo material e aplicar conhecimentos prévios, o leitor acaba por chegar a uma nova forma de manipular (navegar!) o objeto novo, que passa, então, a fazer parte de um universo de possibilidades que jamais será fechado (RIBEIRO, 2011, p.131).

E nesse contexto, no espaço educativo, as práticas pedagógicas, estarão melhor centradas, no momento em que for possível realmente "estar trabalhando na direção de incorporar novos saberes/modos de conhecer (...) Desse modo, aqueles que fazem a 'cultura escolar' devem refletir sobre como incorporar as novas tecnologias" (GOULART, 2011, p.55).

Indubitavelmente, a questão dos suportes de leitura tem relevância no processo de ensino/aprendizagem; contudo, tal discussão faz sentido, à medida que seja gerida paralelamente à criação de 
condições a professores e alunos para viver em sociedade, nesta sociedade que ora temos.

\section{REFERÊNCIAS}

BALTAR, M. Letramento radiofônico na escola. Linguagem em (Dis)curso. Tubarão/ RS, v. 8, n. 3, p. 563-580, set./dez. 2008.

CAVALLO, G.; CHARTIER, R. (Orgs.). História da leitura no mundo ocidental. São Paulo: Ática, 2002. (v.1)

CHARTIER, R. A aventura do livro: do leitor ao navegador: conversações com Jean Lebrun. São Paulo: Editora Unesp, 1998.

CORRÊA, J. Novas tecnologias da informação; novas estratégias de ensino/aprendizagem. In: COSCARELLI, C. V. (Org.) Novas tecnologias, novos textos, novas formas de pensar. Belo Horizonte: Autêntica, 2006, 43-50.

COSCARELLI, C. V.; RIBEIRO, A. E. (Orgs.) Letramento digital: aspectos sociais $\mathrm{e}$ possibilidades pedagógicas. Belo Horizonte: Autêntica, 2011.

COSCARELLI, C. V. Entre textos e hipertextos. In: COSCARELLI, C. V. (Org.) Novas tecnologias, novos textos, novas formas de pensar. Belo Horizonte: Autêntica, 2006, p.6584.

GOULART, C. Letramento e novas tecnologias. In: COSCARELLI, C. V.; RIBEIRO, A. E. (Org.) Letramento digital: aspectos sociais e possibilidades pedagógicas. Belo Horizonte: Autêntica, 2011, p. 42-58.

KLEIMAN, A. (Org.). Os significados do letramento: uma nova perspectiva sobre a prática social da escrita. Campinas: Mercado de Letras, 1995.
MARCUSCHI, L. A. Questão do suporte dos gêneros textuais. 2003. In: http://bbs.metalink. com.br/ lcoscarelli/GEsuporte.doc. Acesso em: 20/07/2014.

MARQUES NETO, H. T. A tecnologia da informação na escola. In: COSCARELLI, C. V. (Org.) Novas tecnologias, novos textos, novas formas de mpensar. Belo Horizonte: Autêntica, 2006, p. 51-64

PARANÁ. Secretaria de Estado da Educação. Diretrizes Curriculares de Língua Portuguesa para os anos finais do Ensino Fundamental e Ensino Médio. Curitiba/PR: SEED, 2009.

RIBEIRO, A. E. Ler na tela-Letramento e novos suportes de leitura e escrita. In: COSCARELLI, C. V.; RIBEIRO, A. E. (Org.) Letramento digital: aspectos sociais e possibilidades pedagógicas. Belo Horizonte: Autêntica, 2011, p.125-150.

RIBEIRO, A. E. Textos e hipertextos na sala de aula. In: COSCARELLI, C. V. (Org.) Novas tecnologias, novos textos, novas formas de pensar. Belo Horizonte: Autêntica, 2006, 85-91. ROJO, R. Letramentos digitais: a leitura com réplica ativa. Trab. Ling. Aplic., Campinas, (46): 63-78, Jan/Jun. 2007.

SANTOS, G. L. A internet na escola Fundamental: sondagem de uso por professores. Educação e Pesquisa. São Paulo. V.29. p.303-312. Julho/dez. 2003.

SOARES, M. Letramento: um tema em três gêneros. Belo Horizonte: Autêntica, 2005.

Novas práticas de leitura e escrita: letramento na cibercultura. Educação \& Sociedade. Centro de Estudos Educação e Sociedade - Vol. 23, n. 81. São Paulo: Cortez: Campinas: Cedes, 2002.

Recebido para publicação em 30 de Jun. 2014. Aceito para publicação em 22 de maio 2015. 